\title{
La radio glocal cross-media: la alternativa ante la reducción de espacios de proximidad local en la radio convencional
}

\section{Cross-Media Glocal Radio: the alternative to the reduction of local proximity spaces in the conventional radio}

\author{
Dr. José María Chomón Serna \\ Prof. Grado de Comunicación Audiovisual \\ (Universidad de Burgos)
}

Fecha de recepción: 20 de agosto de 2015

Fecha de revisión: 25 de diciembre de 2015

Para citar este artículo: Chomón Serna, J.M. (2016): La radio glocal crossmedia: la alternativa ante la reducción de espacios de proximidad local en la radio convencional, Icono 14, volumen (14), pp. 258-286. doi: 10.7195/ ri14.v14i1.894 


\section{MONOGRÁFICO}

\section{Resumen}

Las cadenas radiofónicas españolas, Ser, Onda Cero, Cope y RNE (Radio 5 Todo Noticias) compiten por la reducción de la proximidad local, sin reparar en las consecuencias y fijando como objetivo los recortes económicos.

Las cadenas radiofónicas, mediante un proceso de mimetismo, aplican una misma pauta de programación local, y tienden a instaurar un nuevo modelo radiofónico: la "radio-periódico". Este modelo supone la pérdida de dos de las principales características de la radio: la inmediatez y la cercanía.

La estrategia de reducción de contenidos locales no supone en este contexto una contradicción si se compensa mediante las herramientas que propicien que el "prosumer" acceda a contenidos "glocales", facilitando la actividad cross-media y el relato transmedia.

Palabras clave: Información - Proximidad - Radio-periódico - Inmediatez - Crossmedia - Transmedia

\section{Abstract}

The Spanish radio stations Ser, Onda Cero, Cope and RNE (Radio 5 Todo Noticias) compete for the reduction of local proximity, without thinking about the consequences and setting the economic cutbacks as the only objective.

The radio stations, through a mimicry process, make use of the same pattern of local schedule, having established a new radio model: the radio-newspaper.

This model means the loss of two of the main radio features: The immediacy and the nearness.

The reduction of local content strategy does not mean, in this context, a contradiction if it is offsetting by the tools that propitiate the access of the "prosumer" to "glocal" contents, making easier the cross-media activity and the transmedia stories.

Key Words: Information - Proximity - Radio-newspaper - Immediacy - Cross-media Transmedia 


\section{Introducción}

El 16 de noviembre de 2014 un incendio destruyó por completo la factoría de Campofrío en Burgos. Cientos de vecinos de barrios colindantes tuvieron que ser desalojados de sus viviendas y varios centenares de trabajadores y sus familias se concentraron en las proximidades de la factoría, preocupados por su futuro. La noticia no pudo ofrecerse en la programación local de las principales cadenas radiofónicas españolas con presencia en Burgos, al no disponer ese día de espacios de proximidad local por ser domingo.

Las cuatro grandes cadenas radiofónicas españolas por tamaño y audiencia, Ser, Onda Cero, Cope y RNE, llevan años aplicando una estrategia de reducción y supresión de los espacios locales en su programación convencional con una clara finalidad económica: reducir los gastos para tratar de equilibrar la cuenta de resultados.

A pesar de esta situación, son numerosos los autores que destacan la importancia de lo próximo como un ámbito de experiencia inmediata, de acción, de conocimiento directo, donde la información y los contenidos locales, además de ser los más cercanos, determinan en mayor medida el entendimiento que el ciudadano posee de la realidad, (Almuiña et al, 2008: 210; Cebrián, 2007: 225; Chaparro 1998: 17; Pardo, 2013:106; Tamarit, 2006: 401).

Paralelamente a la reducción de los contenidos de proximidad, las cadenas radiofónicas se incorporan a las plataformas digitales, lo que posibilita la interactividad entre emisor y receptor y hace posible la radio glocal, entendida ésta como aquella especializada en contenidos locales, que gracias a las herramientas de Internet se difunde a nivel global y que tiene la posibilidad de ofrecer, al mismo tiempo, contenidos globales de interés para las sociedades locales.

En general los humanos tenemos un concepto muy reducido del territorio. Todos pertenecemos a un espacio personal, cuyas dimensiones varían en función de la cultura. Sentimos como nuestro el pueblo, el barrio o a lo sumo, la gran ciudad en la que vivimos. A medida que el territorio se amplía, provincia, comunidad, Estado... nuestro concepto territorial se desvanece (Bermúdez de Castro, 2010: 163-164). 


\section{MONOGRÁFICO}

A esta realidad de identidad con el territorio y la cultura a la que se pertenece, se suma la vocación universalista de homo glocal, que lleva aparejada también la relación y el interés por otros espacios: un continente, un país, una región, una provincia, una localidad... y todos estos ámbitos se interrelacionan. Lo global y lo local no son mundos excluyentes, al contrario, ambos son necesarios y convenientes, se retroalimentan y se necesitan. Por ello la evolución, propiciada por la tecnología hacia el homo glocal, requiere de contenidos locales y globales.

La estrategia de reducción de los espacios de proximidad local en la programación convencional de las grandes cadenas radiofónicas no supone en este contexto una contradicción si se compensa mediante las herramientas que propicien que el prosumer -entendido como un usuario activo, crítico y exigente, que participa de forma activa en los medios 2.0- acceda a los contenidos glocales, facilitando la actividad cross-media y el relato transmedia.

El concepto cross-media implica crear y producir contenidos para que, parcial o totalmente, puedan transmitirse y consumirse a través de más de un medio 0 dispositivo (Soto, 2013: 141). Se trata por tanto de una narración integrada a través de diversos medios y que los receptores han de consumir para experimentar el relato completo. El modelo replicante de producir un mismo relato que de forma mimética se distribuye en múltiples plataformas no es suficiente.

El concepto transmedia supone la existencia de uno o varios relatos y su extensión a múltiples plataformas diferentes a la original. Se trata de una experiencia que añade algo más a la historia. Ya no estamos ante el mensaje unidireccional emisor-receptor, sino que este último participa de forma activa en el proceso de comunicación.

La implantación de la radio glocal cross-media con potencialidad transmedia, puede constituir una solución eficaz y eficiente ante la nueva realidad de disminución de los contenidos de proximidad local.

Los cibermedios constituyen un proceso que va de un productor emisor de contenidos y servicios informativos, mediante la plataforma Internet, hasta llegar 
a unos usuarios que pueden seguir, manejar o producir otras informaciones y entablar diálogo o intercambiarse los papeles con el emisor. Se parte de una concepción de los cibermedios como procesos diferentes a los de los medios de comunicación tradicionales. Sin embargo no son radicalmente opuestos, sino que se establecen diversas vinculaciones entre unos y otros (Cebrián, 2009: 16).

La radio se ha sabido adaptar a la evolución tecnológica. Lo hizo con éxito cuando tuvo que afrontar la competencia de la televisión, y en la actualidad se encuentra en pleno proceso de transformación. La evolución ha supuesto pasar, en una etapa inicial, de una "mera ocupación del ciberespacio" (Franquet, 1999: 281), a la aparición de una nueva radio glocal pensada para Internet, que ayuda a "fomentar la interacción y la participación entre emisor y receptor y entre receptores" (Peñafiel, 2007: 25).

La transposición de la radio convencional a Internet, el proceso que Prata denominó "radiomorphosis" (2008: 75-76), ha supuesto el enriquecimiento de la comunicación radiofónica con nuevas estrategias y contenidos. La "radiomorphosis" altera y reconfigura los géneros y las formas de interacción de la radio. La radio hertziana se reconfigura a una webradio y esto significa que coexisten varios formatos en soportes diferentes.

La convergencia entre la radio y las redes sociales, junto al uso del texto, la imagen o el vídeo, tiene como resultado la construcción de los contenidos mediáticos alrededor de la participación e interacción entre los oyentes-usuarios y los productores radiofónicos. Desde una perspectiva transmedia, las redes sociales “han permitido a los oyentes-usuarios convertirse en seguidores de las cadenas, de sus programas, y de los comunicadores radiofónicos" (Piñeiro, 2014:10-12), e interactuar y pasar a ser protagonistas del proceso de comunicación. La radio cross-media y su potencialidad transmedia se constituye como la forma natural de evolución de la radio interactiva.

Como señala Haye (2011, párr. 4), “el usuario puede decidir hasta dónde quiere llegar en la lectura del texto, expandiendo o limitando sus movimientos entre medios diversos. Se abre al público la posibilidad de participar en la creación, aunque esa alternativa resulta difícil de verificar". 
La radio cross-media es una realidad que aprovecha las nuevas tecnologías para entablar una nueva relación con los usuarios. Supone una manera diferente de elaborar los contenidos. La evolución se convierte de esta forma en revolución. La Cadena Cope utilizó audio, vídeo, texto y fotografía para ofrecer un reportaje multimedia (\#traslavalla) para narrar la historia de seis inmigrantes que intentaban saltar la valla que les separaba de España.

Todas las grandes cadenas radiofónicas españolas adaptan sus plataformas para smartphones, tabletas, ordenadores... y ofrecen contenidos de audio, vídeo, imagen fija, texto, hipertexto, radio en directo, perfiles en redes sociales, podcast, blogs... La radio cross-media aprovecha lo mejor de cada soporte para facilitar la distribución de contenidos y la relación con los prosumidores, es decir, "con los usuarios que no sólo se limitan a actuar como consumidores sino que también interactúan y crean contenidos" (García, Del Hoyo \& Fernández, 2014: 36).

Esta radio cross-media facilita la narrativa transmedia, al tener capacidad para elaborar y distribuir contenidos que dispongan de una estructura narrativa diferenciada que se expanda a través de diferentes lenguajes verbales o icónicos y de diferentes soportes, de tal forma que los diferentes medios y lenguajes participen y contribuyan a la construcción del mundo narrativo transmediático (Scolari, 2009: 587).

Ello implica producir contenidos adaptados a cada plataforma a los que el prosumidor podrá acceder en textos e hipertextos, completar con los podcast, imágenes o vídeos y servirse de las redes sociales para profundizar, interactuar y completar el relato.

No se trata de una mera reproducción, lo que Costa, Rodríguez y López (2015: 268) denominan "periodismo replicante". Es necesario que cada plataforma ofrezca algo nuevo, para que el conjunto del relato se enriquezca y los prosumidores contribuyan a completarlo.

Se cambia de esta forma, no solo la manera tradicional de elaborar, estructurar y enviar el mensaje, sino las nuevas formas de consumo e interacción con los oyentes o usuarios de las webs radiofónicas. 
El prosumer radiofónico accede y busca contenidos de su interés, y puede hacerlo en varias plataformas, sin ser esclavo del tiempo de emisión convencional. "El emisor ya no puede imponer una temporalidad discursiva y es cada oyente el que tiene el protagonismo para recrear el tiempo del relato, que organizará según su lógica personal" (García González, 2013: 258).

El prosumer interactúa con el emisor y el mensaje, puede añadir contenidos, los distribuye por diversos canales. Incluso puede aportar su propio relato y convertirse en emisor, comenzando de esta forma un nuevo proceso de comunicación. En la radio y la televisión informativa, el llamado periodismo ciudadano está siendo esencial para acceder y completar los relatos. Sin sus aportaciones algunos contenidos se perderían, no se conocerían o, simplemente, no se completarían. El prosumidor "tiene capacidad de crear desde fuera y desde dentro del relato. Para ello es necesario que los proyectos transmedia contengan apartados donde los usuarios puedan ejercer su labor productora" (Guardia 2014: 268).

El modelo unidireccional pierde de esta forma protagonismo y la interacción se multiplica (Martínez y Amoedo, 2012: 167) y ello porque desde que comenzaron a utilizarse por las radios españolas las redes sociales, en la temporada 2009-2010 (Peña y Pascual, 2013: 124), se ha cimentado un nuevo espacio para construir la relación con la audiencia. "La comunidad de una determinada cadena de radio ya no sólo la conforman sus radioescuchas, sino que la conforma también su audiencia social" (Videla y Piñeiro, 2013: 86).

Estas nuevas herramientas digitales posibilitan a los usuarios generar contenidos y convertirse en prosumers, aunque sigue siendo el medio "el responsable de generar los contenidos" (Gutiérrez, Martí, Ferrer, Monclús, \& Ribes, 2014: 420).

Las redes sociales y las diferentes plataformas digitales, a pesar de su vocación universal, han contribuido a crear proximidad con los usuarios, y se han convertido en instrumentos de acercamiento de la audiencia radiofónica. Aparece de esta forma una nueva radio de proximidad, que puede producirse en cualquier parte del mundo y que permite estar al tanto de lo próximo y de lo lejano y escuchar la radio mientras se navega por Internet y se interactúa. 
Los oyentes glocales ya no dependen solo de la emisión radiofónica tradicional. Con las nuevas tecnologías (TIC) no existe ya una brecha clara entre emisor y receptor como sucede con los medios de comunicación convencionales (Busquet, 2008: 155).

A pesar de ser los principales perjudicados por la reducción de espacios radiofónicos de proximidad, su condición de prosumers y la evolución de la radio convencional hacia la radio glocal cross-media, les puede posibilitar la oportunidad de buscar, aceptar, rechazar y completar los contenidos. De esta forma, con la radio glocal cross-media, lo próximo y lo global forman una alianza que convierte más que nunca lo glocal en una oportunidad en la lucha de las empresas radiofónicas por las audiencias.

\section{Material y métodos}

Para realizar el presente estudio se acude a examinar la literatura científica sobre las nuevas plataformas cross-media y la narrativa transmedia. Además, se utilizan fuentes primarias de tipo cuantitativo y cualitativo.

El estudio analiza la evolución de las parrillas de la programación local de las cadenas radiofónicas, seleccionadas por criterio de importancia según la audiencia (EGM). Ello permite apreciar el aumento/disminución de los contenidos de proximidad local en la emisión convencional de las radios.

Se ha realizado un muestreo cuantitativo, que incluye la totalidad de las emisoras que componen la Cadena Ser, Onda Cero, Cope y RNE. Se desarrolla también un análisis cualitativo de las plataformas de cada una de las emisoras locales, para establecer las que disponen de web, textos, imágenes, redes sociales, podcast, blogs... y el grado de implementación existente.

Con ello se pretende establecer el proceso de implantación de la radio glocal cross-media con potencialidad transmedia. A estos efectos se considera radio glocal cross-media aquella que reúne unos requisitos mínimos, como son la posibilidad de distribución de contenidos en múltiples plataformas (smartphones, 
tablets, ordenadores...); la disponibilidad de una plataforma web participativa, con contenidos de proximidad textual, hipertextual y de audio; la existencia de perfiles en las redes sociales; la emisión de la programación por Internet; así como la integración de otros elementos, como son los podcast, blogs... Estos requisitos mínimos son los que permiten al prosumer de contenidos glocales establecer una relación de interactividad, participar en la interpretación y extensión de los contenidos y contribuir a la formación del relato en diferentes plataformas $\mathrm{y}$ con distintos usuarios.

El objetivo es poder determinar si el aumento/descenso de la programación de proximidad va acompañado de la creación de plataformas radiofónicas cross-media, tanto en la cadena principal como en cada una de las emisoras que la configuran. Se trata de comprobar si, ante la nueva realidad de la radio convencional que disminuye contenidos de proximidad local, se dispone de un nuevo modelo de radio que aporte la posibilidad de buscar el relato radiofónico/informativo y de participar de forma activa en su construcción y distribución en varias plataformas y con distintos usuarios.

Se acude además a un caso real sucedido en Burgos el 16 noviembre de 2014, cuando se incendió la factoría de Campofrío. Las emisoras locales, al no disponer de emisión por ser domingo, informaron del grave suceso a través de las emisiones autonómicas y nacionales y también, en algunos casos, de la red social Twitter. Se estudia en este caso, la distribución de la información por plataformas diferentes a la radio convencional local.

\subsection{Las audiencias}

Para determinar las cadenas objeto del presente estudio se acude a las cuatro de mayor audiencia, según la oleada de octubre de 2014 a mayo de 2015 del Estudio General de Medios (EGM). La Cadena Ser se sitúa en primera posición, con una audiencia, de lunes a domingo, de 4,44 millones de oyentes diarios, mientras que Onda Cero ocupa la segunda posición, con 2,39 millones, seguida de la Cope, con 1,81 millones, y de RNE, con 1,23 millones. 


\section{3 . Resultados}

\subsection{Evolución de la programación e implantación de los soportes digitales en las cadenas radiofónicas españolas}

La totalidad de las cadenas radiofónicas españolas generalistas han emprendido el camino de la reducción de contenidos de proximidad en sus radios locales convencionales. La reducción de espacios locales se configura como una medida adoptada con la finalidad de ajustar y reducir gastos, en detrimento de la información y los contenidos de proximidad, que pierden peso en la parrilla de programación.

Paralelamente a esta realidad, se observa cómo las principales cadenas radiofónicas implementan herramientas tecnológicas que fomentan la radio cross-media, no solo en el ámbito nacional, donde en todos los casos estudiados se encuentran muy implantadas, sino también en los ámbitos geográficos de proximidad.

\subsection{Cadena Ser: Evolución de la programación convencional}

La Cadena Ser, la más importante por número de oyentes, ha apostado por la reducción de la parrilla de programación local. De lunes a viernes la programación de proximidad local vespertina ha sido eliminada y sustituida por espacios que se realizan desde las cabeceras autonómicas. También se ha suprimido la totalidad de la programación local en los fines de semana y festivos, en los que se mantiene programación nacional y algunos espacios autonómicos.

Cualquier acontecimiento que se produzca por las tardes, que no tenga la suficiente trascendencia como para ser emitido en ámbitos más globales, podrá ser ofrecido de forma muy breve en el único boletín local de tres minutos. Si se registra en los fines de semana o festivos deberá esperar hasta el día inmediato laborable. Se produce en este caso un mimetismo con los medios impresos, que ofrecen las noticias del día anterior. La falta de programación local crea la radio-periódico, que existe cuando no hay alternativa para ofrecer los contenidos cuando éstos se producen. 


\begin{tabular}{|c|c|c|c|}
\hline \multicolumn{2}{|c|}{ Programación 2007-2008 } & \multicolumn{2}{|c|}{ Programación 2014-2015 } \\
\hline Hora & Programa & Hora & Programa \\
\hline $07: 20$ a $07: 30$ & Informativo local & $07: 20$ a $07: 30$ & Informativo local \\
\hline 08:20 a 08:30 & Informativo local & $08: 50$ a $09: 00$ & Informativo local \\
\hline $10: 30$ a $10: 33$ & Boletín local & $10: 30$ a $10: 33$ & Boletín local \\
\hline $12: 30$ a $14: 00$ & Programa local & $12: 20$ a $14: 00$ & Programa local \\
\hline $14: 15$ a $14: 30$ & Informativo local & $14: 15$ a $14: 30$ & Informativo local \\
\hline $15: 30$ a $16: 00$ & Deportes local & $15: 30$ a $16: 00$ & Deportes local \\
\hline \multirow[t]{2}{*}{$19: 05$ a $20: 00$} & Programa local & & \\
\hline & & $08: 27$ a $08: 30$ & Boletín local \\
\hline $22: 55$ a $22: 58$ & Boletín local & & \\
\hline $23: 55$ a $23: 58$ & Boletín local & & \\
\hline
\end{tabular}

Tabla 1: Programación de lunes a viernes. Fuente Cadena Ser

La Cadena Ser mantenía en la parrilla de la temporada 2007-2008, de lunes a viernes, un total de 220 minutos diarios de espacios locales (el 15,28 por ciento del total de la programación). En 2014-2015 estos contenidos suponen 171 minutos (un 11,88 por ciento). En términos porcentuales la programación de proximidad local se ha visto reducida en un 3,4 por ciento.

\subsubsection{Implantación de la radio cross-media en el ámbito local de la Ser}

La plataforma de la Cadena Ser dispone de una radio cross-media muy completa que reúne todos los requisitos para propiciar la radio y los relatos transmedia. 
Oferta la emisión en directo en Internet, podcast de programas y contenidos relevantes, perfiles en redes sociales, plataformas de intercambio de contenidos, canal en you tube, vídeos, blogs... y todo ello adaptado a su distribución en múltiples plataformas. Esta radio cross-media con capacidad transmedia no se extiende de igual forma a su red de emisoras locales. En su página web la Cadena Ser muestra 53 "zonas geográficas", que, a su vez, en algunos casos, disponen de varias emisoras en el territorio provincial. Por ejemplo, la zona geográfica de Burgos dispone de emisoras en la capital y en las localidades de Aranda de Duero y Miranda de Ebro, estas últimas como asociadas. De esta forma el total de la red de emisoras propias y asociadas, según consta en la web de la Ser, lo configuran132 emisoras.

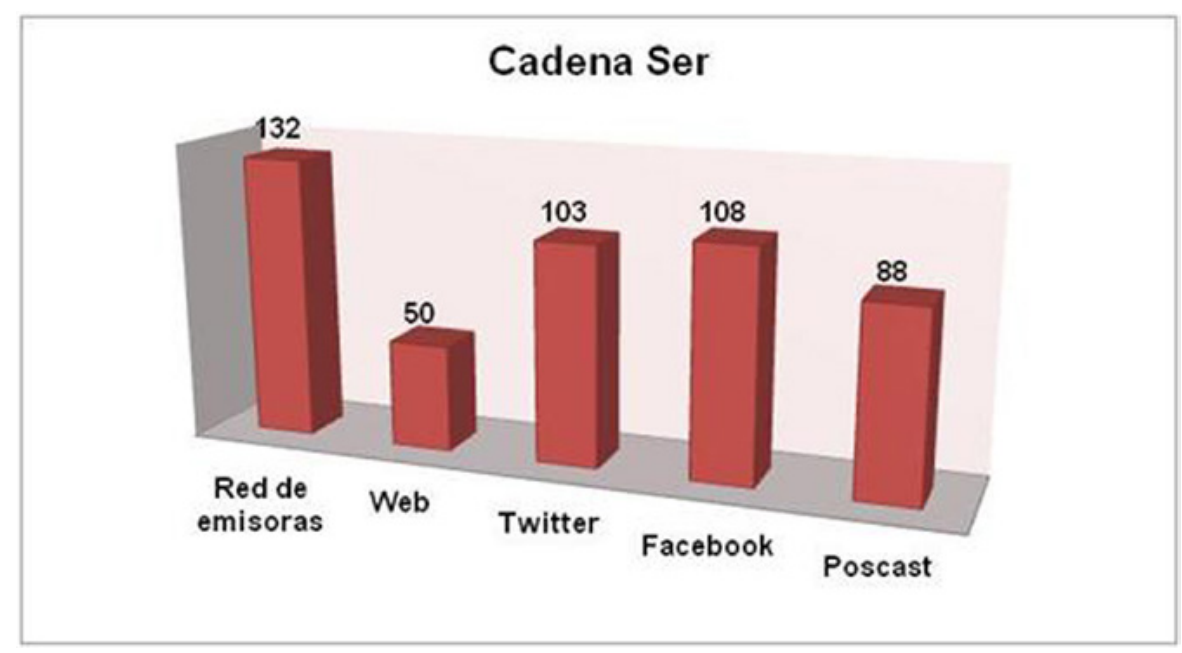

Gráfico 1: Elaboración propia

De todas ellas, 50 disponen de página web, lo que representa un $37,8 \%$ de la red de emisoras, aunque cinco son blogs que aportan exclusivamente textos sin imágenes y sin ningún tipo de interacción posible. De las 132 emisoras, 104 ofrecen también su programación convencional a través de la web oficial de la Ser, y otras 15 lo hacen en sus propias plataformas, mientras que 13 no ofrecen emisión en Internet. Tan sólo 3 de las 50 webs incorporan, además de imágenes y textos, vídeos.

El $66,6 \%$ ofrece podcast, posibilitando con ello que los usuarios puedan acceder a los contenidos radiofónicos estableciendo su propio tiempo de escucha o una configuración personal de los mismos. El 81,8\% ofrece perfil en Facebook y el 78\% en Twitter. 
Como conclusión puede señalarse que la radio cross-media implantada en la Cadena Ser en su plataforma nacional es muy completa, mientras sólo alcanza a 37 emisoras de proximidad local y autonómica (algunas capitales autonómicas, como Pamplona, Cantabria y Mallorca, no disponen de web). Ello supone que el 27,8 por ciento de las emisoras locales de la Ser se pueden considerar como incipientes "radios glocales cross-media".

El resto, el 72,2\%, (95 emisoras) se pueden considerar como radios convencionales locales. Aunque son mayoritarias las que disponen de perfil en las redes sociales, lo que facilita cierto grado de interactuación, tienen deficiencias importantes, como es la ausencia de una web interactiva, de podcast o de emisión en directo a través de Internet.

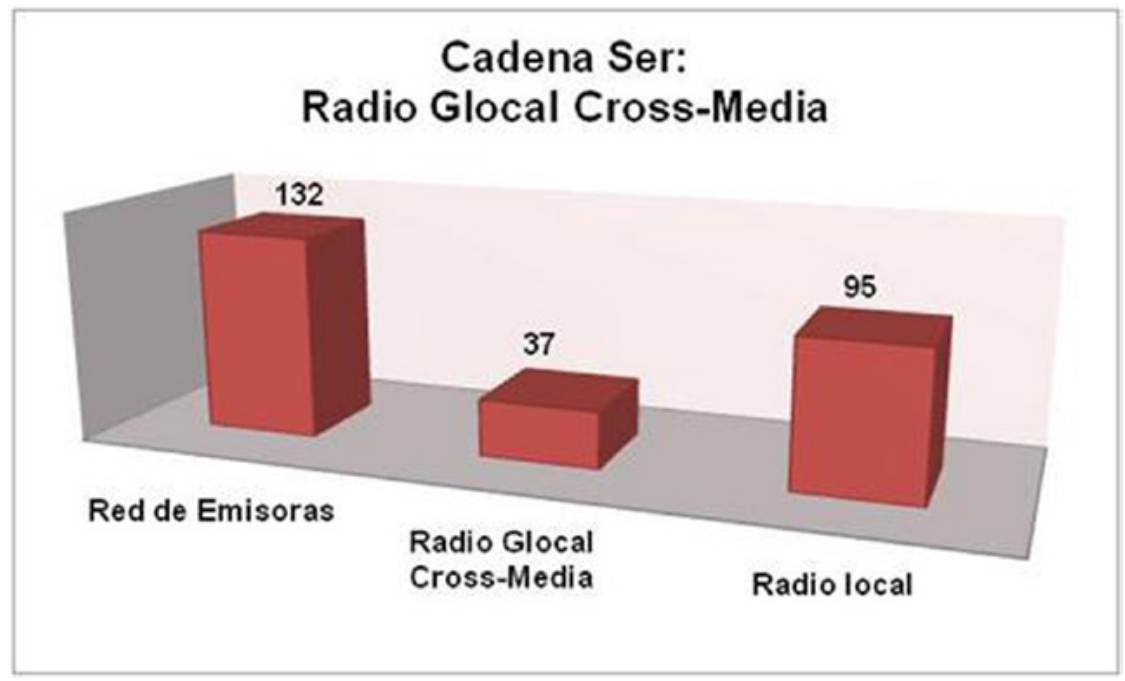

Gráfico 2: Elaboración propia

\subsection{Onda Cero: Evolución de la programación convencional}

Onda Cero, la segunda cadena española en cuanto a número de oyentes, ha reducido sensiblemente su programación local desde la temporada 2007-2008. De los 231 minutos diarios de lunes a viernes, que representaban un 16,04\% del total de la parilla, en la temporada 2014-2015 ofertó 165 minutos, un 11,46 por ciento. Es la única cadena, que junto a la Ser, dispone de un boletín por las tardes. El grueso 


\section{MONOGRÁFICO}

de la reducción de la proximidad local se ha llevado a cabo en la programación vespertina. Los fines de semana y festivos no hay ninguna programación local ni autonómica.

\begin{tabular}{|c|c|c|c|}
\hline \multicolumn{2}{|c|}{ Programación 2007-2008 } & \multicolumn{2}{|c|}{ Programación 2014-2015 } \\
\hline Hora & Programa & Hora & Programa \\
\hline 07:55 a 08:00 & Boletín local & 07:55 a 08:00 & Boletín local \\
\hline $08: 20$ a $08: 30$ & Informativo local & $08: 20$ a $08: 30$ & Informativo local \\
\hline 08:55 a 08:00 & Boletín local & & \\
\hline $10: 55$ a $11: 00$ & Boletín local & $10: 55$ a $11: 00$ & Boletín local \\
\hline $12: 30$ a $13: 50$ & Programa local & $12: 35$ a $13: 50$ & Programa local \\
\hline $13: 50$ a $14: 00$ & Informativo local & $13: 50$ a $14: 00$ & Informativo local \\
\hline $15: 05$ a $16: 00$ & Deportes local & $15: 05$ a $16: 00$ & Deportes local \\
\hline $16: 57$ a $17: 00$ & Boletín local & & \\
\hline $19: 05$ a $20: 00$ & Programa local & & \\
\hline $20: 20$ a $20: 23$ & Boletín local & $20: 20$ a $20: 25$ & Boletín local \\
\hline
\end{tabular}

Tabla 2: Programación de lunes a viernes. Fuente Onda Cero

\subsubsection{Implantación de la radio cross-media en el ámbito local de Onda Cero}

Onda Cero dispone de una web interactiva con contenidos actualizados, emisión en directo a través de Internet, podcast, perfiles en redes sociales, canal en you tube... y adaptada para su distribución en diferentes soportes, smartphones, tabletas, ordenadores... Reúne con ello los requisitos para poder ser considerada como una radio cross-media con potencialidad transmedia. 
En su página web, 0nda Cero dispone de un total de 68 emisoras, de ellas nueve aparecen como "emisoras destacadas" (Madrid, Castellón, Sevilla, Aragón, Cataluña, Murcia, País Vasco, Valladolid, Galicia, Pamplona, Mallorca y Málaga).

Tan solo tres emisoras (4,4 por ciento), las de Vigo, Santander y Pamplona, disponen de página web. Podcast ofrecen 45 emisoras $(66,2$ por ciento), mientras que perfil en Twitter tienen 50 (73,5 por ciento) y en Facebook 59 (86,7 por ciento).

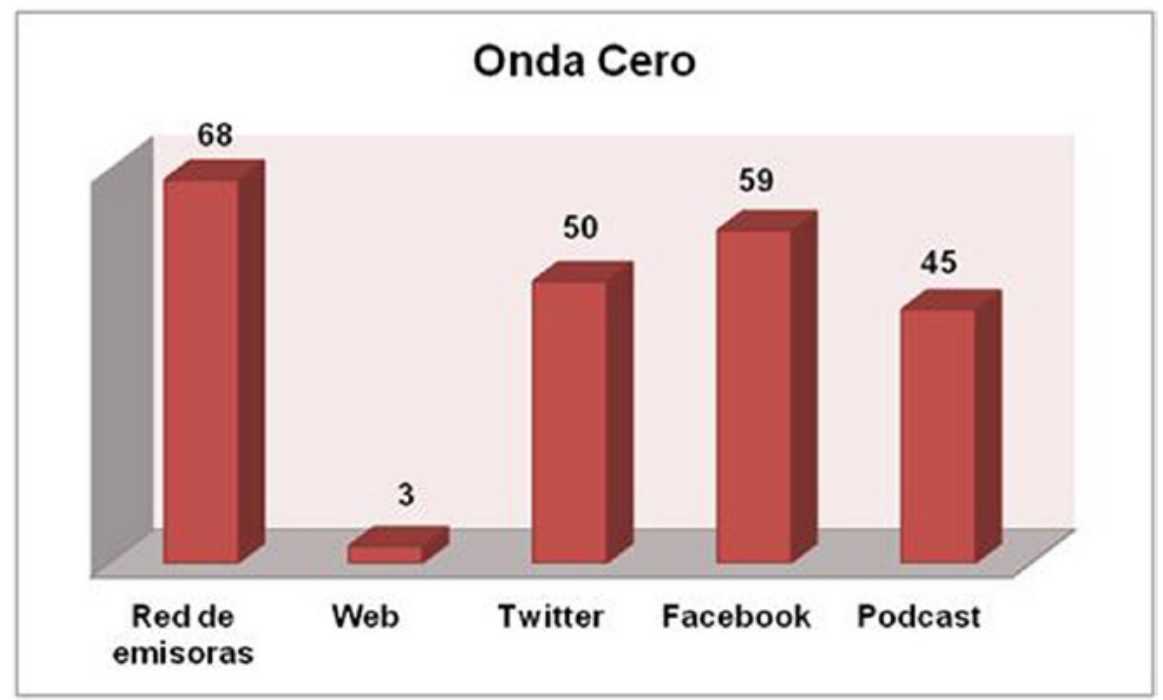

Gráfico 3: Elaboración propia

Ninguna emisora de la cadena tiene web interactiva con contenidos de proximidad actualizados. Las tres webs disponibles no reúnen este requisito. A través de la web de Onda Cero se puede acceder a la programación en directo de las 68 emisoras de la cadena.

Como conclusión puede establecerse que, a pesar de que hay cierto grado de interactividad, al estar implantados perfiles en las redes sociales, no existe en 0nda Cero ninguna emisora local que pueda considerarse radio glocal croos-media. La falta de programación local durante los fines de semana imposibilita la inmediatez en la oferta de contenidos de proximidad, actuando en estos periodos temporales como una radio-periódico. 


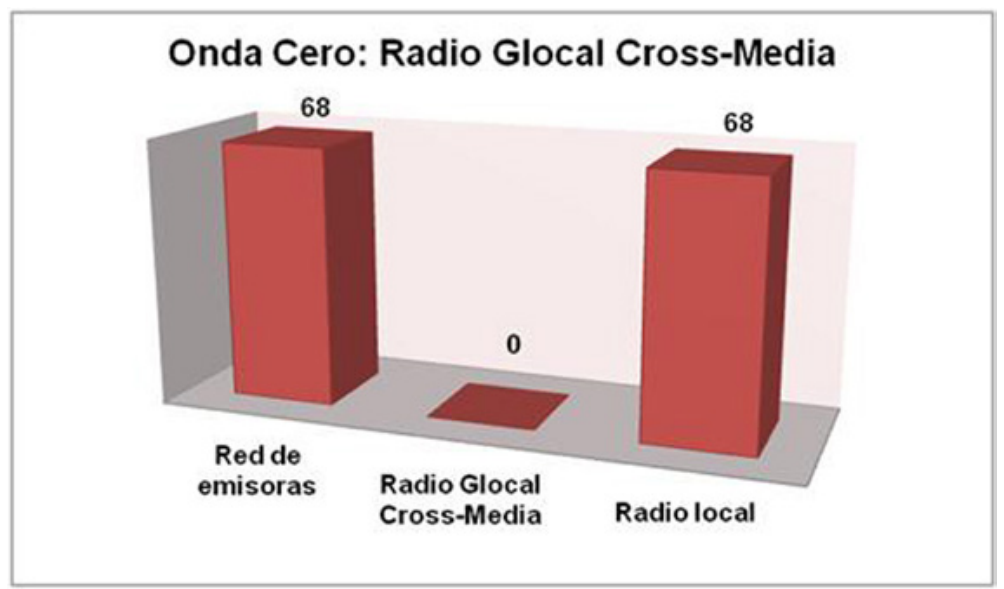

Gráfico 4: Elaboración propia

\subsection{Cadena Cope: Evolución de la programación convencional}

La Cope, tercera por número de oyentes, es la que menos espacios de proximidad local ofrece en su parrilla de programación entre las cadenas privadas. Los fines de semana no hay programación local ni autonómica.

\begin{tabular}{|c|c|c|c|}
\hline \multicolumn{2}{|c|}{ Programación 2007-2008 } & \multicolumn{2}{c|}{ Programación 2014-2015 } \\
\hline Hora & Programa & Hora & \\
\hline 07:55 a 08:00 & Boletín local & & Brograma \\
\hline & & $08: 05$ a 08:06 & Boletín local \\
\hline $08: 20$ a 08:30 & Informativo local & $08: 25$ a 08:30 & Informativo local \\
\hline & & $09: 05$ a 09:06 & Boletín local \\
\hline & & $10: 05$ a 10:06 & Boletín local \\
\hline $12: 15$ a 13:35 & Programa local & $12: 30$ a 13:30 & Brograma local \\
\hline
\end{tabular}




\begin{tabular}{|c|c|c|c|}
\hline \multicolumn{2}{|c|}{ Programación 2007-2008 } & \multicolumn{2}{c|}{ Programación 2014-2015 } \\
\hline Hora & Programa & Hora & Programa \\
\hline $13: 50$ a 14:00 & Informativo local & $14: 20$ a $14: 30$ & Informativo local \\
\hline $14: 40$ a $15: 00$ & Deportes local & $15: 20$ a $16: 00$ & Deportes local \\
\hline $19: 30$ a $20: 00$ & $\begin{array}{c}\text { Programa local (lunes, } \\
\text { miércoles y jueves) }\end{array}$ & & \\
\hline
\end{tabular}

Tabla 3: Programación de lunes a viernes. Fuente Cadena Cope

La Cope ha pasado de ofrecer en la temporada 2007-2008, de un total de 143 minutos diarios de lunes a viernes de programación local, lo que suponía el 9,93 por ciento del total de la parrilla, a ofertar 119 minutos en la temporada 2014-2015, lo que representa un 8,26 por ciento. Los fines de semana y festivos no hay programación local ni autonómica. Se configura de esta forma durante los fines de semana y todas las tardes de lunes a viernes como una radio-periódico local, al no tener posibilidad de narrar lo que acontece en esos períodos temporales.

\subsubsection{Implantación de la radio cross-media en el ámbito local de la Cope}

La Cadena Cope dispone de una web interactiva con información actualizada, perfiles en las principales redes sociales, radio en directo por Internet, podcast, blogs, canal en you tube... y adaptada para su distribución en diferentes plataformas. Esta cadena reúne los requisitos para estar considerada como una radio cross-media con potencialidad transmedia. Los usuarios pueden escuchar la radio convencional o hacerlo por Internet, compartir y crear contenidos en las redes sociales, incluido el canal de you tube, acceder a los audios más destacados de la cadena y a contenidos de texto e imagen en su web.

Esta adaptación cross-media no lo es tanto cuando se accede a las emisoras locales de la cadena. Según su web, la Cope cuenta con 67 emisoras que configuran su red en toda España. De ellas 20, lo que representa un 29,8 por ciento, disponen 


\section{MONOGRÁFICO}

de web; 58 (86,6 por ciento) de perfil en Twitter; 56 (83,6 por ciento) con perfil en Facebook y 54 (80,6 por ciento) facilitan podcast con sus contenidos. A través de la web de la Cope se puede acceder a la programación en directo de 61 emisoras, lo que representa el 91 por ciento.

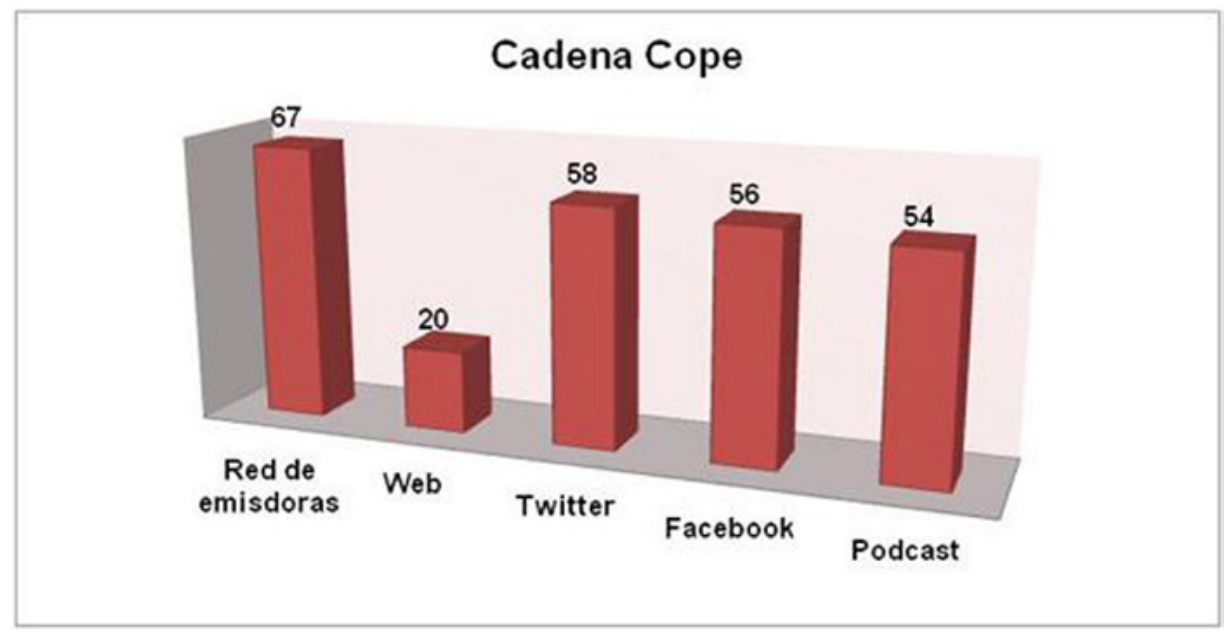

Gráfico 5: Elaboración propia

La radio glocal cross-media tiene una implantación muy débil. De las 20 emisoras con web, 11 no reúnen los requisitos de disponer de contenidos de proximidad actualizados. Entre las nueve emisoras con webs interactivas actualizadas, perfiles en redes sociales, podcast... hay otra, la de Gandía, cuya programación no se oferta desde la web de la cadena, aunque se hace desde su propia plataforma web.

Como conclusión puede indicarse que de las 67 emisoras de la cadena, 9 tienen capacidad para ofertar una radio glocal cross-media. Ello representa el 13,4 por ciento de la totalidad.

De estos datos se concluye que la radio glocal cross-media se encuentra en proceso de implantación, pero lejos todavía de conseguir alcanzar unos porcentajes mayoritarios dentro de la cadena. 


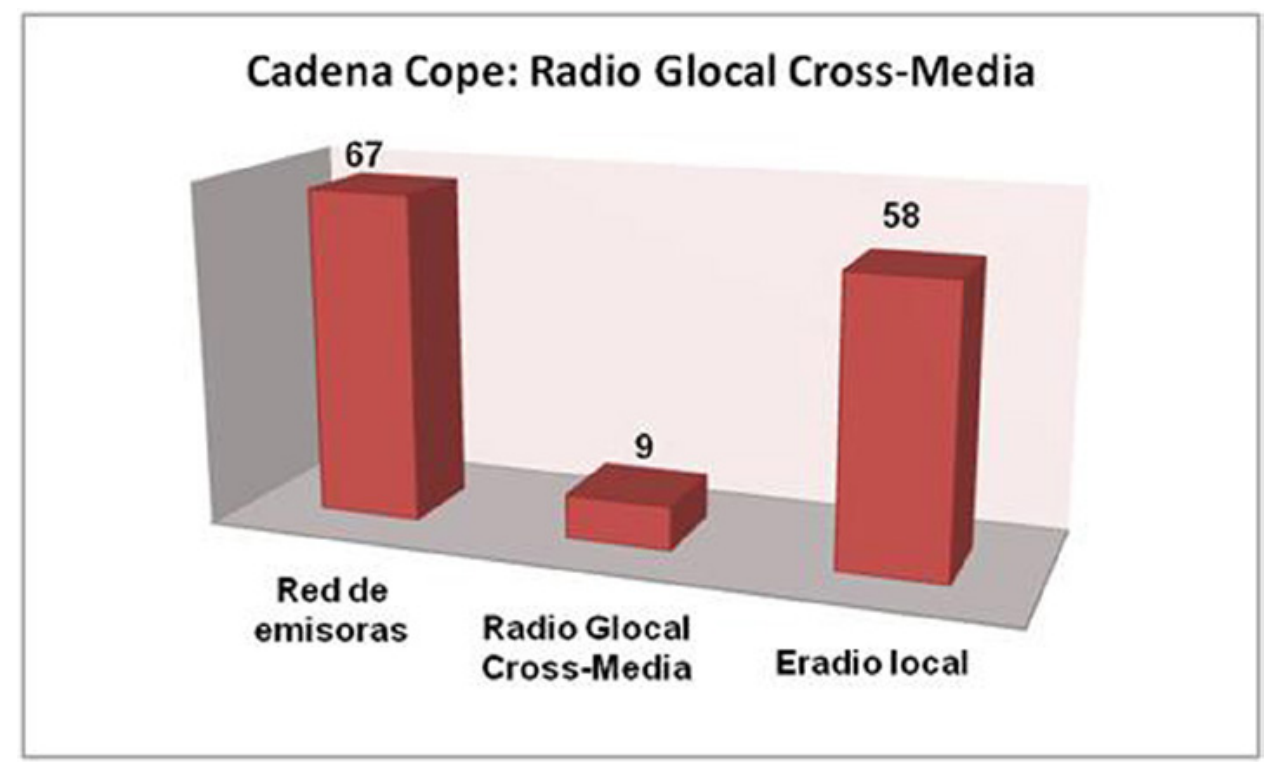

Gráfico 6: Elaboración propia

\subsection{RNE: Evolución de la programación convencional}

Radio Nacional de España -Radio 1- (RNE) nunca ha ofertado programación local. Este cometido lo ha desempeñado históricamente Radio Cadena Española, convertida en 1988 en Radio 5, que en 1994 se reconvirtió en Radio 5 Todo Noticias (R5TN). La programación de la red de emisoras provinciales y territoriales de R5TN ha variado desde su creación, de tal forma que en 1994 llegó a ofrecer 23 boletines diarios de 5 minutos de carácter local y 24 autonómicos (Chomón, 2012: 39).

Con el ERE de 2006 se suprimió sustancialmente la programación y contenidos de proximidad local, que quedaron reducidos a un informativo matinal de $15 \mathrm{mi}$ nutos, que se ha emitido en diferentes horarios (08:45 a 09:00; de 09:00 a 09:15; de 0915: a 09:30...) Este espacio de 15 minutos se amplió en la temporada 2013 a dos informativos con el mismo tiempo cada uno, con un total de 30 minutos que se mantienen en la temporada 2014-2015 en horario matinal. 


\begin{tabular}{|c|c|c|c|}
\hline \multicolumn{2}{|c|}{ Programación 2007-2008 } & \multicolumn{2}{c|}{ Programación 2014-2015 } \\
\hline Hora & Programa & Hora & Programa \\
\hline 08:45 a 09:00 & Informativo local & $08: 45$ a 09:00 & Informativo local \\
\hline & & $09: 30$ a 10:45 & Informativo local \\
\hline
\end{tabular}

Tabla 4: Programación de lunes a viernes. Fuente RNE

\subsubsection{Implantación de la radio cross-media en el ámbito local de RNE}

RNE no dispone de una web propia e individualizada, sino que está integrada en la de RTVE. El apartado de radio ofrece la programación de cada una de las cadenas nacionales que configuran la radio estatal pública. Se oferta además la emisión en directo de la programación nacional a través de Internet, y diversos contenidos textuales e icónicos, así como perfiles en las redes sociales, y los podcast de espacios nacionales y autonómicos, estos últimos los informativos territoriales de cada comunidad autónoma.

Se trata de una web corporativa muy completa, que reúne todos los requisitos cross-media y con altas prestaciones para la configuración de relatos transmedia. Sin embargo las emisoras locales de RNE no disponen de web, ni de perfiles propios en las redes sociales, podcast... Tampoco se ofrece en la web la relación de emisoras locales ni la emisión de su programación en Internet.

RNE es una cadena que no ha iniciado el proceso para la implantación de la radio glocal cross-media. La red de emisoras de Radio 5, bajo la denominación de Unidades Informativas, se encuentran integradas en los diferentes Centros Territoriales (cabeceras autonómicas), con un director que gestiona la emisora regional y la red provincial.

\subsection{El caso de Campofrío}

El domingo 16 de noviembre de 2014 la ciudad de Burgos se vio sacudida por un incendio de grandes dimensiones, que supuso la completa destrucción de la 
factoría que la multinacional cárnica de Campofrío tenía en la capital burgalesa. El balance del siniestro, según datos oficiales, se tradujo en unos 170 millones de euros en pérdidas y la incertidumbre para cerca de un millar de trabajadores directos $\mathrm{y}$ varios miles indirectos.

La noticia no pudo ofrecerse dentro de la programación local de ninguna de las emisoras de las cadenas nacionales de radio en Burgos. Los fines de semana, al igual que en los festivos, ninguna de las grandes cadenas mantiene espacios de proximidad local. Las emisoras locales de estas cadenas tampoco abrieron una programación especial para ofrecer información más amplia y detallada a su entorno más próximo.

Mientras las emisoras locales de las cadenas nacionales solo pudieron informar en los boletines informativos nacionales o autonómicos, la demanda de información llevó al Ayuntamiento de Burgos a utilizar su perfil de Twitter para informar a los medios de comunicación y a la población en general del suceso. A las 12:36 el Ayuntamiento emitió el siguiente tuit: “Ante la evolución de los acontecimientos, desde @Aytoburgos utilizaremos esta cuenta para ir facilitando la información, \#incendiocampofrío". Más ágil fue el 112, que a las 08:48 ofreció la siguiente información: "Incendio en las instalaciones de Campofrío en el barrio de \#Gamonal de \#Burgos. Sin heridos de momento. Organismos trabajando en el lugar". Por su parte la propia empresa esperó hasta las 18:19 para emitir el siguiente texto en su cuenta de Twitter: "Comunicado oficial sobre el incendio de nuestra fábrica en Burgos. htp://ow.ly/Em7xR. Gracias a todos por vuestras muestras de ánimo".

La dimensión del siniestro y sus consecuencias llevaron al Ayuntamiento a activar el Plan de Emergencia Municipal. La Policía alertó, vivienda por vivienda, a los habitantes de los barrios de Villafría, Cótar y Castañares para que cerrasen puertas y ventanas y no salieran de sus domicilios, dada la toxicidad de la nube de humo. Unos 400 vecinos de estos barrios tuvieron que ser desalojados de sus viviendas y trasladados provisionalmente a instalaciones municipales. 


\section{MONOGRÁFICO}

Todos estos acontecimientos no pudieron ser incluidos en ningún espacio local de las cadenas Ser, Onda Cero, Cope o RNE (Radio 5 TN). Los oyentes de Burgos tuvieron que seguir la programación nacional o acudir a las redes sociales y a otros medios, entre ellos los digitales.

El gráfico 7 refleja el número de intervenciones que desde Burgos se realizaron en la programación nacional de las cadenas. La Ser y la Cope conectaron con Burgos en once ocasiones cada una, RNE ofreció catorce conexiones a través de sus canales de Radio 1 y Radio 5 Todo Noticias, y Onda Cero conectó en cuatro ocasiones.

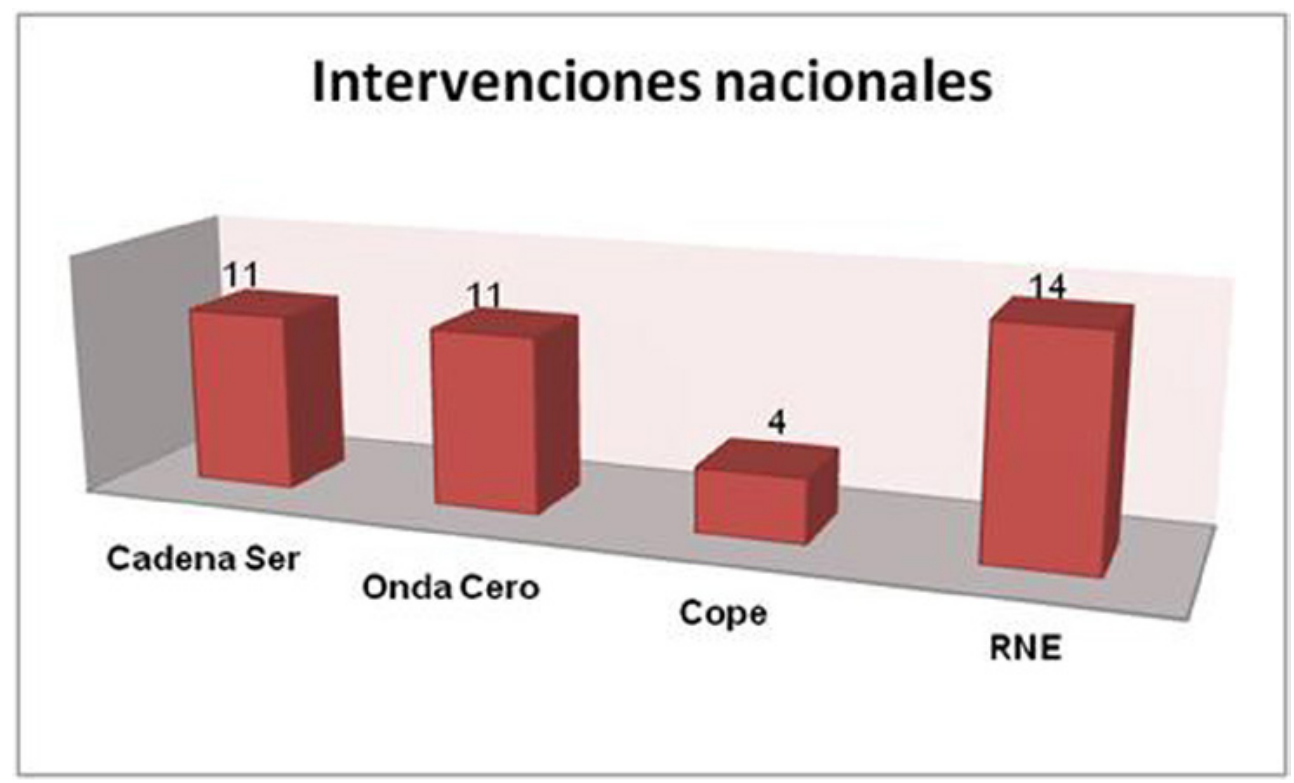

Gráfico 7: Fuente cadenas radiofónicas

Además de en la programación nacional, la Ser y RNE informaron en su programación autonómica. La Cope y 0nda Cero, al no disponer de espacios de proximidad autonómica durante los fines de semana, no pudieron hacerlo. En la Ser se realizaron tres intervenciones, mientras que en RNE se realizó una. 


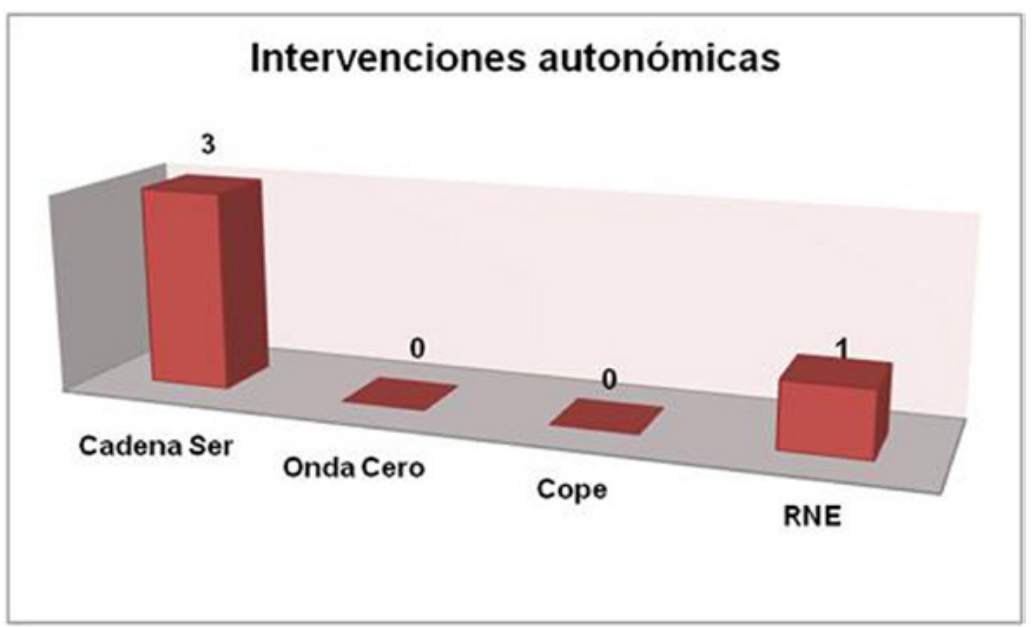

Gráfico 8: Fuente cadenas radiofónicas

Las cuatro emisoras locales pudieron ofrecer información amplia y detallada a partir del lunes 17 de noviembre, dentro de sus espacios matinales locales, al modo tradicional de la prensa escrita, que oferta a sus lectores las noticias del día anterior.

Ante un siniestro de estas dimensiones, las emisoras locales actuaron como meras corresponsalías, poniendo al servicio de la cadena sus equipos humanos y técnicos locales, pero sin autonomía para abrir desconexiones de proximidad.

\subsubsection{El uso de las redes sociales}

Ante la falta de programación local, las plantillas de las emisoras en Burgos cubrieron el evento para ofrecer información en las conexiones radiofónicas nacionales y autonómicas.

Además, utilizaron Twitter para ofrecer información puntual a la población y seguidores de Burgos. La Cadena Ser ofreció 11 tuits y obtuvo 229 retuits y 54 favoritos. Onda Cero Burgos ofreció 6 entradas en Twitter y obtuvo 102 retuits y 27 favoritos. La Cadena Cope realizó 6 entradas y obtuvo 13 retuits y 7 favoritos. Por su parte RNE en Burgos no hizo ninguna entrada al no disponer de perfil en Twitter. 


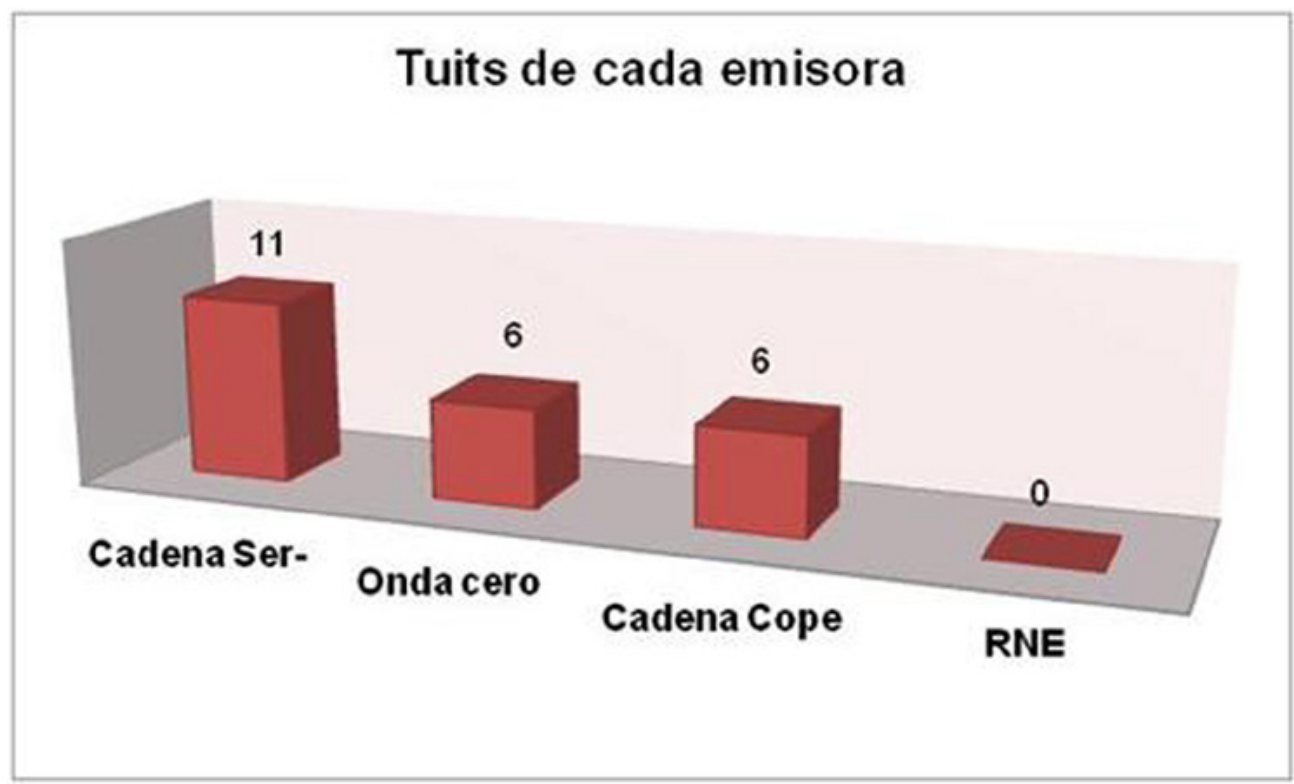

Gráfico 9: Elaboración propia

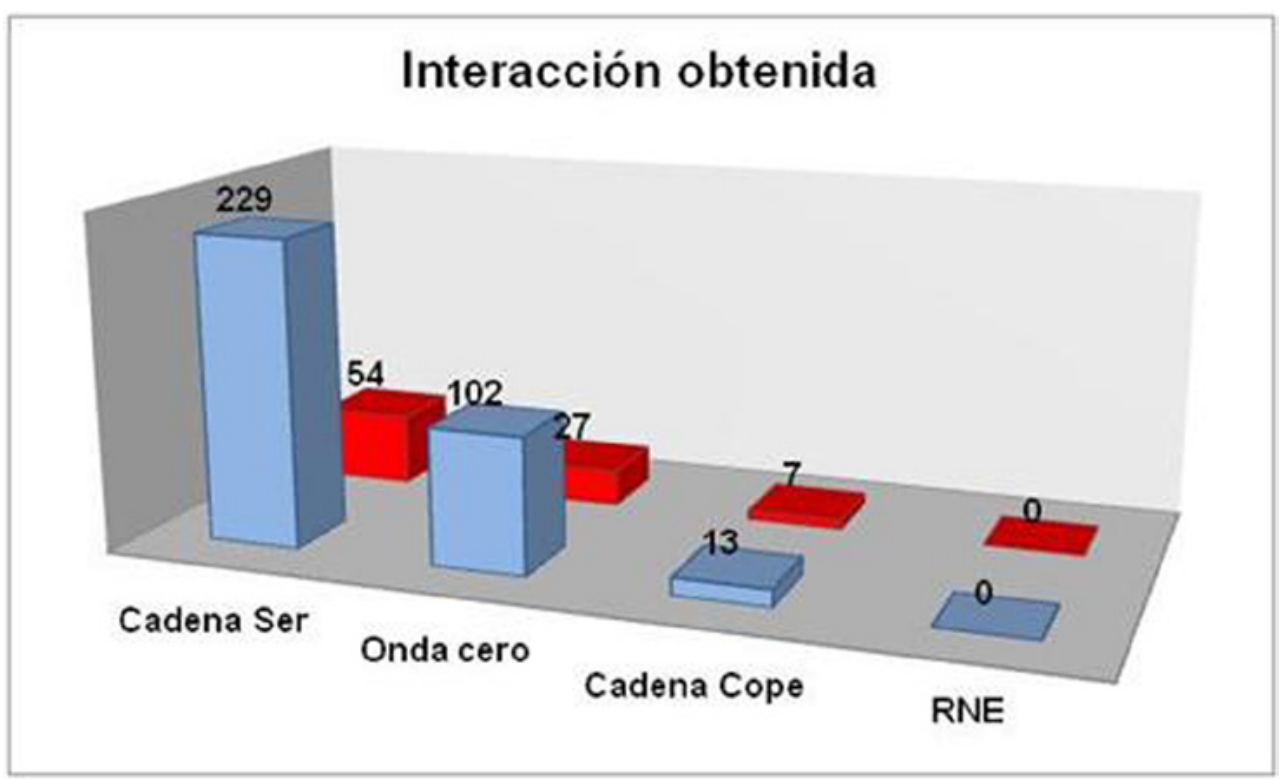

Gráfico 10: Elaboración propia

ICONO14 | Año 2016 Volumen $14 \mathrm{~N}^{\circ} 1$ | ISSN: 1697-8293 | DOI: ri14.v14i1.894 
En el gráfico diez se aprecia la interacción conseguida con las informaciones de las radios locales de Burgos en sus perfiles de Twitter. Se trata de interacciones replicantes.

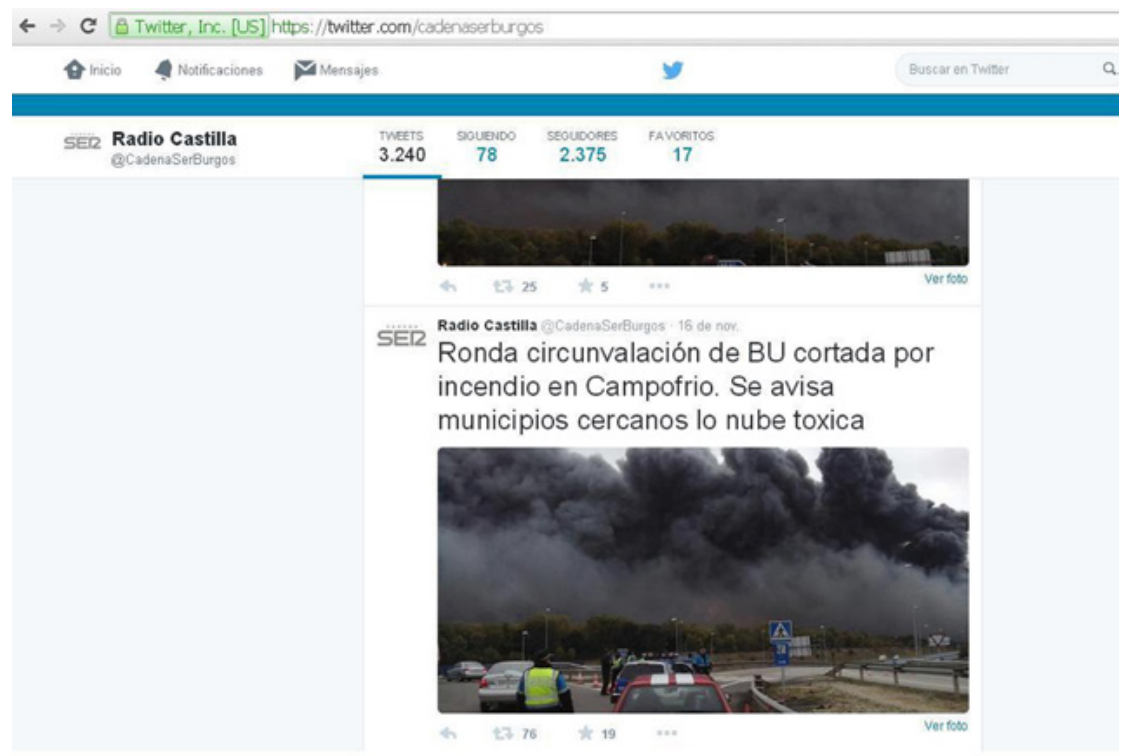

Figura 1: Tweet Cadena Ser en Burgos

SOCIEDADIENBURgos

Un grave incendio arrasa la planta de Campofrío y obliga a evacuar a 400 personas
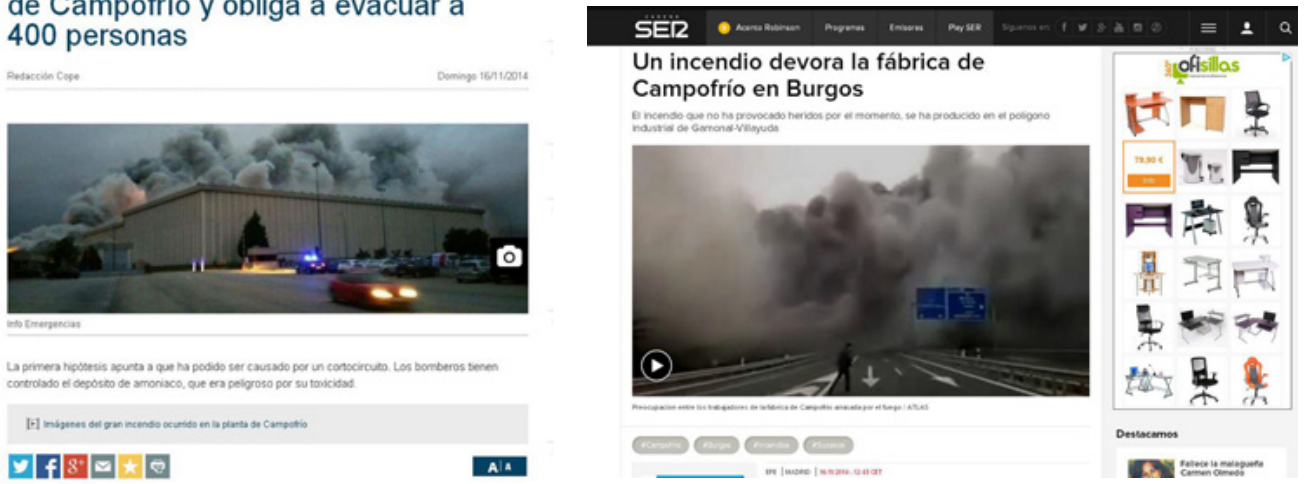

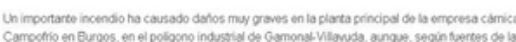

Figura 2: Informaciones ofrecidas en las webs de la Ser y la Cope

DOI: ri14.v14i1.894 | ISSN: 1697-8293 | Año 2016 Volumen 14 N 1 | ICONO14 
Las cadenas Ser, Onda Cero, Cope y RTVE informaron del suceso en sus webs nacionales, aunque ninguna pudo hacerlo en sus webs locales, al no disponer de esta herramienta, por lo que se limitaron a transmitir informaciones de 140 caracteres en Twitter, excepto RNE de Burgos, que no tiene perfiles en las redes sociales.

\section{Discusión y conclusiones}

Cuando la programación convencional, por la supresión de espacios locales, no posibilita la trasmisión de información inmediata, que es una de las principales características de la radio, la disponibilidad de herramientas tecnológicas que faciliten esta labor puede ser una alternativa eficiente para ofrecer a la comunidad social los datos que reclaman. La implementación de la radio glocal cross-media puede convertirse en la mejor de las alternativas posibles.

El prosumer local, ante la falta de espacios y contenidos de proximidad en las radios locales, tendría la posibilidad de acudir a sus plataformas web, bucear en los textos, imágenes, podcast y redes sociales que ofrezcan datos de su interés. Incluso podría completar relatos a los que en ocasiones no llegan los medios. En muchos casos su colaboración permite acceder y distribuir en masa contenidos textuales e icónicos. Es la potencialidad transmedia que completa y perfecciona la radio crossmedia.

Las cuatro cadenas radiofónicas más importantes de España por audiencia, Ser, Onda Cero, Cope y RNE, disponen de plataformas multimedia nacionales, que las convierten en radios cross media con potencialidad transmedia.

Todas han reducido en su red de emisoras la programación de contenidos locales y se encuentran en una fase de adaptación tecnológica constante, aunque esta adaptación no se reparte por igual entre la red de emisoras locales que las configuran.

La radio cross-media implantada en la Cadena Ser, en su plataforma nacional, es muy completa, mientras alcanza parcialmente a 37 emisoras de proximidad, es decir, al 27,8 por ciento de la red de emisoras locales. 
Onda Cero tiene una plataforma cross-media nacional, que no alcanza a las emisoras locales. A pesar de que hay cierto grado de interactividad, al estar implantados perfiles en las redes sociales, no existe ninguna emisora del ámbito local que pueda considerarse como radio glocal croos-media.

En la Cope, de las 67 emisoras de su red, 9 ofertan una radio glocal cross-media con capacidad transmedia, lo que representa el 13,4 por ciento de la totalidad de la cadena. Esta cadena en su plataforma nacional, oferta una completa radio crossmedia.

RNE no ha iniciado ningún proceso para la implantación de la radio glocal crossmedia. Sus emisoras locales (Unidades Informativas), se encuentran integradas en los Centros Territoriales (cabeceras autonómicas). Ni las emisoras locales ni los centros autonómicos disponen de perfiles en las redes sociales, webs, blogs, emisión en directo... Aunque RTVE ofrece la plataforma web interactiva más completa, no se ha iniciado ningún proceso de extensión a la red de emisoras locales y autonómicas.

De todos estos datos se concluye que la radio glocal cross-media se encuentra en proceso de implantación, pero lejos todavía de conseguir alcanzar unos porcentajes mayoritarios y que es la Cadena Ser la que se encuentra con un proceso de implantación más desarrollado.

En el caso de las cadenas analizadas, la falta de espacios de proximidad local las convierten, en algunos periodos temporales, en radio-periódico, ante la imposibilidad de ofrecer en su programación convencional algunos acontecimientos de relevancia para su entorno social en el momento en que se producen. Aunque la mayoría pueden utilizar las redes sociales, sólo una minoría de emisoras disponen de plataformas cross-media para poder adaptarse a la exigencia de inmediatez e interactividad.

\section{Referencias}

Almuiña Fernández, C. (2008). La relevancia de los medios de comunicación en Castilla y León. Valladolid. Consejo Económico y Social de Castilla y León. 
Bermúdez de Castro, J.M. (2010). La evolución del talento. Barcelona. Radom House Mondadori.

Busquet, J. (2008). Reflexiones críticas sobre el mito de la sociedad de masas. Trípodos, 23, 147-160.

Cebrián Herreros, M. (2009). Comunicación interactiva en los cibermedios. Comunicar, 33, 15-24. doi:10.3916/c33-2009-02-001

Cebrián Herreos, M. (2007). Modelos de radio. Desarrollos e innovaciones. Madrid. Fragua.

Costa Sánchez, C., Rodríguez Vázquez, A. I. \& López-García, X. (2015). Del periodismo transmedia al replicante, cobertura informativa del contagio del Ebola en España por El país.com. En El profesional de la información, 24 (3), 282-290. doi: http://dx.doi.org/10.3145/epi.2015.may.08

Costa Sánchez, C. \& Piñeiro Otero, T. (2012). Nuevas narrativas audiovisuales: multiplataforma, crossmedia y transmedia. Icono 14, 10 (2), 102-125. doi: http://dx.doi.org/10.7195/ri14.v10i2.156.

García-Galera, M C., Del Hoyo Hurtado, M. \& Fernández-Muñoz, C. (2014). Jóvenes comprometidos en la Red: El papel de las redes sociales en la participación social activa. Comunicar, 22 (43), 35-43. doi: http://dx.doi.org/10.3916/C432014-03-

García González, A. (2013). De la radio interactiva a la radio transmedia: nuevas perspectivas para los profesionales del medio. Icono 14, 11 (2), 251-267. doi: 10.7195/ri14.v11i2.567

Guardia Calvo, I. (2014). La ruptura del relato en la narración transmedia: creación de espacios para la acción social. Fonseca, Journal of Communication-Monográfico (2), 259-279. Recuperado de: http://revistas.usal.es/index.php/2172-9077/ article/viewFile/12095/12457

Gutiérrez, M., Martí, J.M., Ferrer, I., Monclús, B. y Ribes, X (2014). Los programas radiofónicos españoles de prime time en Facebook y Twitter: Sinergias entre la radio convencional y las redes sociales". Revista Latina de Comunicación Social, 69, 418-434. doi: 10.4185/RLCS-2014-1018

Chaparro, M. (1998). La radio pública local. Madrid. Fragua.

Chomón Serna J.M. (2012). Evolución y transformaciones de Radio 5 Todo Noticias. Una radio menos cercana. Madrid. Fragua.

Franquet, R. (1999). Radio y Televisión en la red: el primer asalto. En Franquet, R., 
y Larrègola, G. (Eds.) Actas I Congreso Internacional Comunicar en la Era Digital (pp. 277-285). Barcelona. Societat Catalana de Comunicació.

Haye, R. (2011). Narrativa transmedial. En Pagina12. Recuperado de: http://www. pagina12.com.ar/diario/laventana/26-164253-2011-03-16.html.

Martínez-Costa, M.P., Moreno, E. \& Amoedo, A. (2012). La radio generalista en la red. Un nuevo modelo para la radio tradicional. Anagramas, 10 (20), 165-180. Recuperado de: http://www.scielo.org.co/pdf/angr/v10n20/v10n20a12.pdf

Nair Prata, M.M. (2008). Web Radio: novos géneros, novas formas de intereçao. (Tesis doctoral). Belo Horizonte. Facultade de letras. - UFMG. Recuperado de: http://www.bibliotecadigital.ufmg.br/dspace/bitstream/handle/1843/AIRR7DDJD8/nair_prata_tese.pdf?sequence $=1$

Peña Jiménez, P. \& Pascual, A. (2013). Redes sociales en la radio española. Facebook, Twitter y Community Management. ZER, 18 (35), 123-144. Recuperado de: http://www.ehu.eus/zer/hemeroteca/pdfs/zer35-06-pena.pdf

Peñafiel Sainz, C. (2007). Transformaciones de la radio y la televisión en Europa. Bilbao: Servicio de Publicaciones Universidad del País Vasco, Bizkaia.

Piñeiro 0tero, T. (2014). La utilización de la Bio para los programas de la radio española en Twitter. De la presentación del perfil a la radio transmedia. Fonseca, Journal of Communication, 8, 9-34. Recuperado de: file:///C:/Documents\%20 and\%20Settings/Casa/Mis\%20documentos/Downloads/11810-43069-1-SM.pdf Scolari, C.A. (2009). Transmedia storytelling: Implicit consumers, narrative worlds, and branding in contemporary media production. International journal of communication, 3 (21), 586-606. Recuperado de: http://ijoc.org/index.php/ ijoc/article/\%20viewFile/477/336

Soto Sanfiel, M.T. (2008). Cross media training (para crear en tiempos de convergencia. Análisi 36, 139-158. Recuperado de: http://www.raco.cat/index. php/analisi/article/viewFile/94528/119743

Tamarit, A.M. (2006): Consideraciones sobre el periodismo local en Castilla y León. Zer, 20, 399-409.

Videla Rodríguez, J.J. \& Piñeiro Otero, T (2013). Hacia una "radio social". Interacción, proyección y repercusión de las cadenas españolas en las redes sociales. Icono 14, 11 (2), 83-113. doi: http://dx.doi.org/10.7195/ri14.v11i2.592 